\title{
PRESENTATION PATTERN AND FUNGAL AGENTS SPECTRUM CAUSING OTOMYCOSIS
}

\author{
KASSIM R. DEKHIL*
}

Department of Surgery, College of Medicine, University of Al-Qadisiyah, Iraq. Email: kassimraisan2@gmail.com

\author{
Received: 07 December 2017, Revised and Accepted: 25 December 2017
}

\begin{abstract}
Objective: This study was aimed to identify the pattern of presentation, influencing factors, and sort of the fungal species, distribution of sex of patients with otomycosis.

Methods: Eighty-six patients attended to Ad-Diwaniyah teaching hospital, Iraq were screened for identification of fungi causing otomycosis from October 2014 to November 2015. 50 patients were females while 36 patients were males. 12 patients of the total number were with bilateral involvement. Diabetes mellitus, leukemia, chemotherapy, and chemoradiation were the associated systemic diseases which were recorded in patients with otomycosis and diabetes mellitus was detected in $53.84 \%$ of patients with systemic diseases.

Results: The predominant complaints were pruritus and found in 76 patients (88.73\%), discomfort and pain found in 62 patients (72.09\%), aural fullness in 48 patients (55.81\%), tinnitus in 34 patients (39.53\%), hearing impairment in 50 cases (58.31\%), ear discharge in 22 patients (25.58\%), and most of the symptoms seen in 36 patients (68.14\%). The results showed a total of eight fungal species belong to six different genera, namely, Aspergillus, Candida, Penicillium, Rhizopus, Alternaria, and Cephalosporium were isolated during this study. Among identified fungi, Aspergillus niger was found to be the most prevalent fungal species with $35.71 \%$ followed by Candida albicans (27.55\%), Aspergillus flavus (10.20\%), Aspergillus fumigatus (8.16), Penicillium digitatum (6.12\%) and Cephalosporium species (4.08\%), and Rhizopus species (5.1\%), while Alternaria alternata had the lowest percentage $(6.54 \%)$.
\end{abstract}

Conclusion: Otomycosis/mycotic otitis externa is still a common problem and there is a rise in the occurrence of otomycosis in latest years, especially in tropical and subtropical humid climates.

Keywords: Otomycosis, Fungal agents, Aspergillus, Candida.

(C) 2018 The Authors. Published by Innovare Academic Sciences Pvt Ltd. This is an open access article under the CC BY license (http://creativecommons. org/licenses/by/4. 0/) DOI: http://dx.doi.org/10.22159/ajpcr.2018.v11i1.24368

\section{INTRODUCTION}

Otitis externa is a generic name for inflammation in living external auditory canal (EAC) that may affect part of the canal but can involve the segment of meatus which extends to tympanic membrane without spreading to the cleft of the middle ear. The problem usually is infectious which may be bacterial or fungal in origin [1-3] but can be associated with different types of non-infectious constitutional or local skin diseases [4]. Warm, dark, and moist setting of the EAC is the perfect medium for rapid growth of bacteria and fungi [5].

The term otomycosis employed to declare a superficial, diffuse fungal infection of the external auditory meatus. It is generally considered to be opportunistic occurring after treatment of bacterial infection and develops unilaterally in healthy persons and in many times a pride posing problem is present [6-8]. It has been found that otitis externa (OE) constitutes about $5-20 \%$ of ear consultations to otorhinolaryngologists; the majority of these cases are caused by bacteria and in $9-25 \%$ fungal agents are the cause and the microorganisms which attribute for these clinical conditions are present as saprobes in nature [9-11]. Otomycosis can be presented with non-specific manifestations such as itching, discomfort and otalgia, aural fullness, tinnitus decrease in hearing and otorrhea [12-15]. There are many factors which may take important roles in fungal infection of the ear like humidity moisture Warmth, darkness and water access into the external auditory canal during bathing decreased immune function, preexisting ear diseases, cleaning of ear wax, and comorbid conditions such as diabetes and dermatological diseases [16-19].

There are many studies which show that there had been a rise in the occurrence of otomycosis in latest years which were linked to the extensive use of antibiotic ear drops, widespread use of corticosteroids, and chemotherapeutic agents $[12,20,21]$. Secondary overgrowth of fungi is well-known and recognized complication of the use of broad- spectrum antibiotics such as fluoroquinolones and cephalosporins $[12,20,22-24]$. Prevalence is also influenced by the geographical area, as otomycosis is most commonly present in tropical and subtropical humid climates [12,13,25-27]. The most common species encountered in cases of otomycosis are Aspergillus and Candida [28-30].

\section{METHODS}

This study was conducted in Ad-Diwaniyah teaching hospital, Diwaniyah city, Iraq, from October 2014 to November 2015. All patients presenting to the outpatient department with a clinical diagnosis of otomycosis agreed with the inclusion criteria were involved in the study. The inclusion standards were patients of either sex, aged beyond 10 years, and consuming features of fungal otitis externa. The patients with a history of chronic otitis media or mastoid cavity were excluded from the study. To determine the genera and species of fungi causing otomycosis, the samples from the ear were put with sterile swab sticks which were appropriately categorized demonstrating the source, name and age of patient, data, and time of collection. All patients were not receiving any local or systemic antibiotics or antifungals at least for the last 3 days. The samples were directly taken to the microbiology laboratory of Ad-Diwaniyah teaching hospital.

\section{Diagnosis}

The swab sticks were streaked directly on the Sabouraud Dextrose Agar plates and incubated at $25 \pm 2 \mathrm{C}$. The growth was visible within 5-7 days. Each fungal growth was identified based on their morphological and cultural characteristics and microscopic examination was done using lactophenol staining technique [31]. The finding of otomycosis was depending on patients giving a green/gray or black discharge besides microscopic examination viewing fungal spores and hyphae. Informed consents were obtained from all patients. 
Statistical analysis

Collected data were analyzed using SPSS (statistical package for the social sciences), version 20. Descriptive analysis of means and standard deviation were calculated on all demographic variables, multiple comparisons of paired series of data within groups were done using ANOVA test. Unpaired $t$-test was then used to evaluate the difference between the two groups. $\mathrm{p}<0.05$ was considered the minimum for statistical significance.

\section{RESULTS}

Of total 86 patients with clinical diagnosis of otomycosis who were submitted for the study, 50 patients were females while 36 patients were males. 12 patients of the total number were with bilateral involvement (Fig. 1).

In this study, the predominant complaints were pruritus and found in 76 patients (88.73\%), discomfort and pain found in 62 patients $(72.09 \%)$, aural fullness in 48 patients (55.81\%), tinnitus in 34 patients (39.53\%), hearing impairment in 50 cases (58.31\%), ear discharge in 22 patients (25.58), and most of the symptoms seen in 36 patients (41.86\%) (Fig. 2).

About 30 cases $(34.88 \%)$ of the tolerant provided a past of handling/ trauma to the EAC with either stick, metallic picker, pin, or other instruments, 21 patients $(24.41 \%)$ provided a past of using either antibiotic ear drops, antibiotic-steroid ear drops, or the use of garlic into the ear. Furthermore, 13 patients $(15.11 \%)$ had related systemic disorders, and 22 patients (25.58\%) had no predisposing factors (Fig. 3).

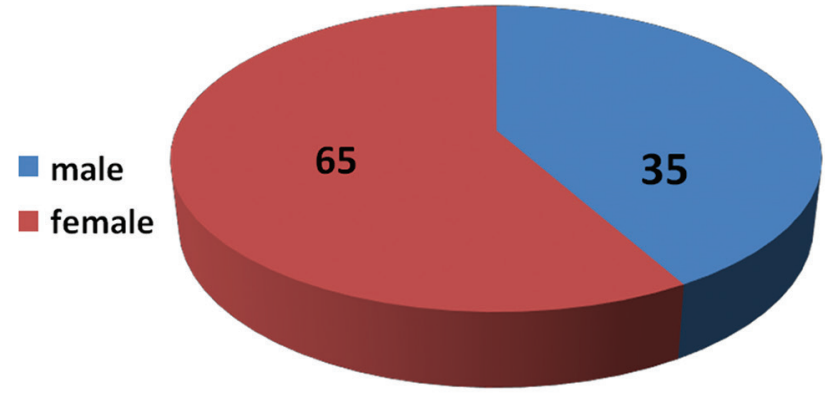

Fig. 1: Sex distribution of otomycosis

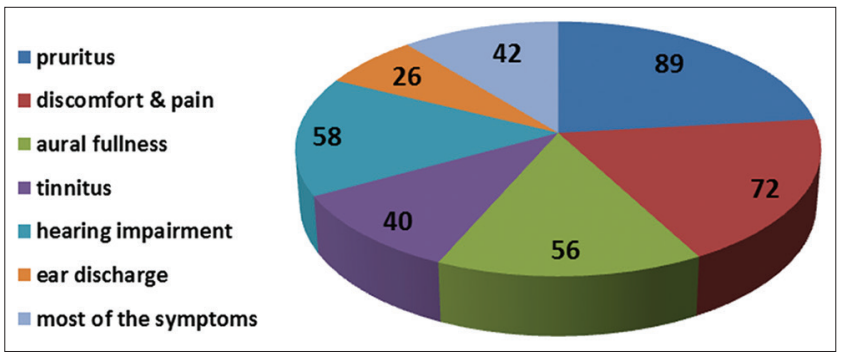

Figure (2) distribution of features

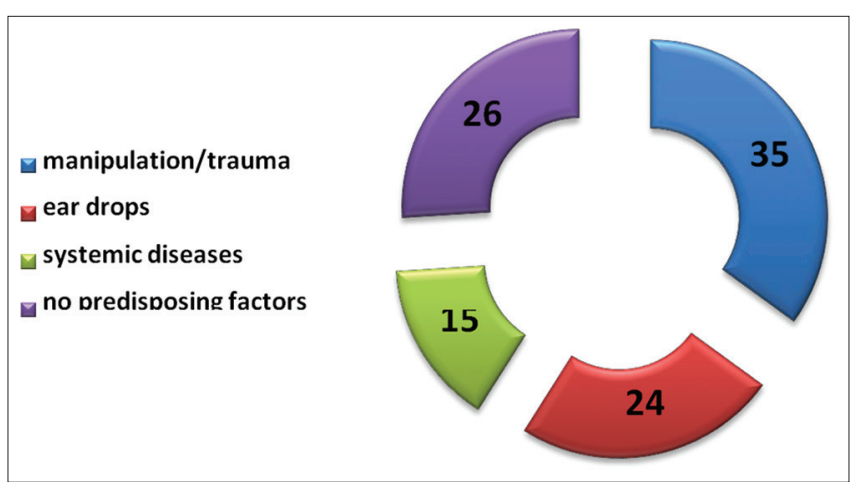

Figure (3) distribution of predisposing factors
Diabetes mellitus was detected in seven patients (53.84\%) of total cases associated with systemic diseases which were recorded in our patients with otomycosis; one case $(7.69 \%)$ was detected in each of leukemia, chemotherapy, kidney transplant and two cases (15.38\%) in patients receiving chemoradiation (Fig. 4 and Table 1).

The results summarized in Table 2 showed a total of eight fungal species belong to six different genera, namely, Aspergillus, Candida, Penicillium, Rhizopus, Alternaria, and Cephalosporium were isolated during this study. Among identified fungi, Aspergillus niger was found to be the most prevalent fungal species with $(35.71 \%)$ followed by Candida albicans (27.55\%), Aspergillus flavus (10.20\%), Aspergillus fumigatus (8.16), Penicillium digitatum (6.12\%) and Cephalosporium species (4.08\%), and Rhizopus species (5.10\%), while Alternaria alternata had the lowest percentage $(3.06 \%)$.

\section{DISCUSSION}

Although there is a controversy with respect to whether fungi are the true infective agents versus mere colonization species as a results of compromised local host immunity secondary to bacterial infection, most clinical and laboratory evidence to date supports otomycosis as a true pathogenic entity, with $C$. albicans and $A$. niger as the most common

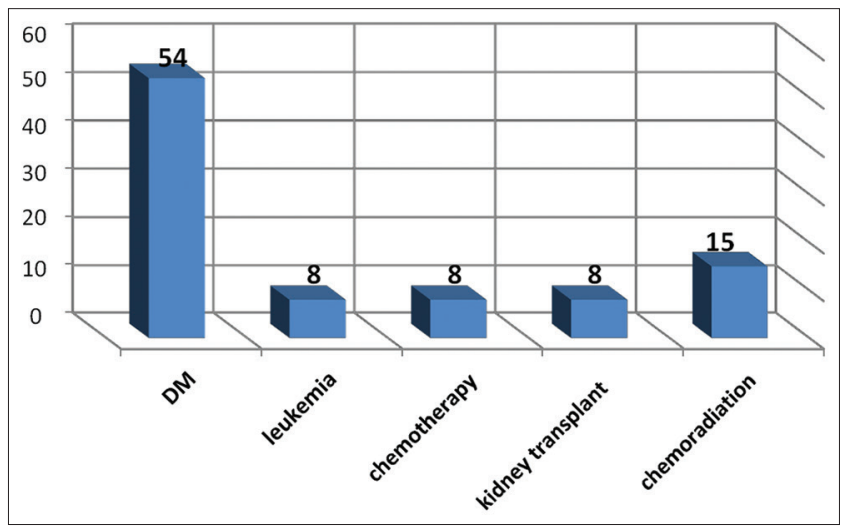

Figure (4) distribution of associated systemic diseases

Table 1: Age range of patients

\begin{tabular}{ll}
\hline Age range in years & Number of patients (\%) \\
\hline $10-20$ & $4(4.65)$ \\
$21-30$ & $8(9.30)$ \\
$31-40$ & $21(24.41)$ \\
$41-50$ & $18(20.93)$ \\
$51-60$ & $15(17.44)$ \\
$61-70$ & $12(13.95)$ \\
Above 71 & $8(9.30)$ \\
Total & $86(100)$ \\
\hline
\end{tabular}

Table 2: Percentage and frequency of fungal infections causing otomycosis

\begin{tabular}{lll}
\hline Fungal isolates & Number of isolates & $\begin{array}{l}\text { Percentage of } \\
\text { occurrence (\%) }\end{array}$ \\
\hline A. niger & 35 & 35.71 \\
C. albicans & 27 & 27.55 \\
A. flavus & 10 & 10.20 \\
A. fumigatus & 8 & 8.16 \\
P. digitatum & 6 & 6.12 \\
Cephalosporium sp & 4 & 4.08 \\
Rhizopus sp. & 5 & 5.10 \\
A. alternate & 3 & 3.06 \\
Total & 98 & $\% 855$ \\
\hline
\end{tabular}

A. niger: Aspergillus niger, C. albicans: Candida albicans, A. flavus: Aspergillus flavus, A. fumigatus: Aspergillus fumigatus, P. digitatum: Penicillium digitatum, $A$. alternate: Alternaria alternate 
fungal species isolated [18,32,33]. Classically, fungal infection is the result of prolonged treatment of bacterial otitis externa that alters the flora of the ear canal, mixed bacterial, and fungal infections are thus common. However, the fungus is occasionally the primary pathogen in otitis externa, especially in the presence of excessive moisture or heat [4].

Study by Jackman et al. [22] assessed the contribution of topical antibiotic ear drops to the development of ear fungal infections, their research had revealed that ofloxacin may contribute to the development of otomycosis in two ways; first, this antibiotic is bactericidal to most bacteria in the external auditory meatus, and fungal proliferation may occur because of the lack of competing for bacterial growth, and second, in contrast to other topical antibiotic ear drops which typically have a $\mathrm{pH}$ of 3-4, ofloxacin ear drops have a $\mathrm{pH}$ of 7 , this is a more neutral solution and will not acidify the $\mathrm{pH}$ of the external auditory canal skin making it a more optimal environment for fungal growth and proliferation (Aspergillus grows optimally at a $\mathrm{pH}$ of 6). These two properties of topical ofloxacin ear drops may explain its association with otomycosis.

The diagnosis of fungal infections of the ear can be challenging given its non-specific symptoms and may be misdiagnosed for other chronic otitis externa conditions. Recurrence after treatment is not uncommon, and eradication of disease can be particularly difficult in some cases $[20,34]$.

Otolaryngologists should remain alert for detection of otomycosis and should consider obtaining culture when this disease is suspected. The findings in this study are in general agreement with the findings observed by earlier workers like Rutt et al. [35] and Ozcan et al. [36].

\section{CONCLUSION}

Otomycosis/mycotic otitis externa is still a common problem and there is a rise in the incidence of otomycosis in latest years, especially in tropical and subtropical humid climates. It presents with non-specific symptoms and so may be misdiagnosed for other chronic otitis externa conditions. The most common species encountered in this study are Aspergillus and Candida.

\section{REFERENCES}

1. Enoz M, Sevinc I, Lapeña JF. Bacterial and fungal organisms in otitis externa patients without fungal infection risk factors in Erzurum, Turkey. Braz J Otorhinolaryngol 2009;75:721-5.

2. Fisher T. Synopsis of Causation: Otitis Externa. London: Queen's Medical Centre Nottingham; 2008.

3. Franke G. An Earful on Treatment, Otitis Externa. Practical Otolaryngology Conference. The Canadian Journal of CME; 2003. p. 146-50.

4. Sander R. Otitis externa: A practical guide to treatment and prevention. Am Fam Physician 2001;63:927-36, 941-2.

5. Bailey JB, Calhoun HK, Deskin WR, Johnson TJ, Kohut IR, Pillsbury III, et al. Head and Neck Surgery-Otolaryngology. $2^{\text {nd }}$ ed. Philadelphia, PA: Lippincott-Raven Publishers; 1998. p. 1967-75.

6. Gleeson M, Browning GG, Burton JM, Clarke R, Hibbert J, Jones SN, et al. Scott-Brown's Otolaryngology, Head and Neck Surgery. $7^{\text {th }}$ ed. London: Edward Arnold; 2008. p. 213-25.

7. Flint PW, Haughey BH, Lund VJ, Niparko JK, Richardson MA, Robbins KT, et al. Cummings Otolaryngology-Head and Neck Surgery. $5^{\text {th }}$ ed. Philadelphia, PA: Mosby Elsevier; 2010, p. 1945-62.

8. Kaufman RS. ENT secrets. Am J Otolaryngol 1998;19(2):144.

9. Karn KP, Lakshmanan A, Hemamalini M, Radha M. Otomycosis: A study from a tertiary care center. J Pharm Res 2014;8:266-8.

10. Nemati S, Hassanzadeh R, Khajeh Jahromi S, Delkhosh Nasrollah Abadi A. Otomycosis in the north of Iran: Common pathogens and resistance to antifungal agents. Eur Arch Otorhinolaryngol 2014;271:953-7.

11. Pontes ZB, Silva AD, Lima Ede O, Guerra Mde H, Oliveira NM,
Carvalho Mde F, et al. Otomycosis: A retrospective study. Braz J Otorhinolaryngol 2009;75:367-70.

12. Satish HS, Viswanatha B, Manjuladevi M. A clinical study of otomycosis. IOSR J Dent Med Sci 2013;5:57-62.

13. KumarA. Fungal Spectrum in Otomycosis Patients. JK Sci 2005;7:152-5.

14. Kiakojuri K, Roushan HR, Sepidgar AA. Suction clearance and $2 \%$ topical miconazole versus the same combination with acidic drops in the treatment of otomycosis. Southeast Asian J Trop Med Public Health 2007;38:749-52.

15. Dorasala PS, Dorasala S. Medicated gelfoam for the treatment of recalcitrant otomycosis. Ind J Otol 2013;19:18

16. Abdelazeem M, Gamea A, Mubarak H, Elzawawy N. Epidemiology, causative agents, and risk factors affecting human otomycosis infections. Turk J Med Sci 2015;45:820-6.

17. Panchal P, Pethani J, Patel D, Rathod S, Shah P. Analysis of various fungal agents in clinically suspected cases of otomycosis. Ind J Basic Appl Med Res 2013;2:865-9.

18. Kaur R, Mittal N, Kakkar M, Aggarwal AK, Mathur MD. Otomycosis: A clinicomycologic study. Ear Nose Throat J 2000;79:606-9.

19. Stern JC, Lucente FE. Otomycosis. Ear Nose Throat J 1988;67:804-5, 809-10.

20. Ho T, Vrabec JT, Yoo D, Coker NJ. Otomycosis: Clinical features and treatment implications. Otolaryngol Head Neck Surg 2006;135:787-91.

21. Hueso Gutiérrez P, Jiménez Alvarez S, Gil-Carcedo Sañudo E, GilCarcedo García LM, Ramos Sánchez C, Vallejo Valdezate LA, et al. Presumption diagnosis: Otomycosis. A 451 patients study. Acta Otorrinolaringol Esp 2005;56:181-6.

22. Jackman A, Ward R, April M, Bent J. Topical antibiotic induced otomycosis. Int J Pediatr Otorhinolaryngol 2005;69:857-60.

23. Lee KJ. Infections of the Ear in Essential Otolaryngology-Head and Neck Surgery. $8^{\text {th }}$ ed. New York: McGraw-Hill; 2003. p. 470-2.

24. Moghadam YA, Asadi AM, Dehghani R, Mahmoudabadi ZA, Rayegan $\mathrm{F}$, Hooshyar $\mathrm{H}$, et al. Evaluating the effect of a mixture of alcohol and acetic acid for otomycosis therapy. Jundishapur J Microbiol 2010;3:66-70.

25. Khan F, Muhammad R, Khan RM, Rehman F, Iqbal J, Khan M, et al. Evaluation of the therapeutic efficiency of topical clotrimazole and topical miconazole in the treatment of otomycosis. J Ayub Med Coll Abbottabad 2013;25:78-80

26. Alnawaiseh S, Almomani O, Alassaf S, Elessis A, Shawakfeh N, Altubeshi K, et al. Treatment of otomycosis: A comparative study using miconazole cream with clotrimazole otic drops. J Ramanujan Math Soc 2011;18:34-7

27. Bineshian F, Irajian G, Koochak-Alavi KS, Fredonian RM. A study on the frequency of fungal agents in otitis externa in semnan. Iran J Pathol 2006;:1:141-4

28. Anwar K, Gohar SM. Otomycosis; clinical features, predisposing factors, and treatment implications. Pak J Med Sci 2014;30:564-7.

29. Zaror L, Fischman O, Suzuki FA, Felipe RG. Otomycosis in são paulo. Rev Inst Med Trop Sao Paulo 1991;33:169-73.

30. Sivamani P. Otitis externa Fungal isolates and their sensitivity to essential oils of selected herbals. Int J Curr Microbiol Appl Sci 2014;3:415-29.

31. Collins CH, Lyne PH. Microbiological Methods $5^{\text {th }}$ ed. Ibadan: Butter worth and co-publisher Ltd.; 1984. p. 300-41.

32. Lucente FE. Fungal infections of the external ear. Otolaryngol Clin North Am 1993;26:995-1006.

33. Vennewald I, Schönlebe J, Klemm E. Mycological and histological investigations in humans with middle ear infections. Mycoses 2003; $46: 12-8$

34. Swarup RJ, Shah AW, Mohan M, Sathyaki DC, Mannur S, Nazir F, et al. Otomycosis-mycological spectrum, etio-pathological factors and management. J Evol Med Dent Sci 2014;3:4850-8.

35. Rutt A, Sataloff L, Robert T. Aspergillus otomycosis in immunocompromised patients. Ear Nose Throat J 2008;87:145-5613.

36. Ozcan M, Ozcan KM, Kararshan A. Concomitant otomycosis and dermatomycosis: A clinical and microbiological study. Ear Arch Otorhinolaryngol 2010;260:24-7. 